journal homepage: http://chimie-biologie.ubm.ro/carpathian_journal/index.html

\title{
THE EFFECT OF PROBIOTICS, PREBIOTICS AND SYNBIOTICS IN FORMULA MILK TOWARDS THE INCIDENCE OF ACUTE RESPIRATORY INFECTION ON 1-5 YEARS OLD HEALTHY CHILDREN IN DAY CARE CENTRES
}

\begin{tabular}{|c|c|}
\hline \multicolumn{2}{|c|}{$\begin{array}{l}{ }^{1} \text { Department of Child Health, Dr. Soetomo Hospital, Faculty of Medicine, Universitas Airlangga, } \\
\text { Surabaya, Indonesia } \\
\text { *rezagunadi@gmail.com }\end{array}$} \\
\hline Article history: & ABSTRACT \\
\hline $\begin{array}{l}\text { Received: } \\
\text { 9 March } 2019 \\
\text { Accepted: } \\
\quad 20 \text { September } 2019\end{array}$ & $\begin{array}{l}\text { The incidence and the transmission of acute respiratory infection (ARI) in } \\
\text { children, especially those at daycare centres (DCCs), are still high. The aim } \\
\text { of this study is to investigate whether probiotics, prebiotics, or synbiotics in } \\
\text { formula milk can lower the incidence and duration of ARI in healthy }\end{array}$ \\
\hline $\begin{array}{l}\text { Keywords: } \\
\text { probiotics; } \\
\text { prebiotics; } \\
\text { synbiotics; } \\
\text { respiratory infection; } \\
\end{array}$ & $\begin{array}{l}\text { children at DCCs. This randomized, double-blind, and placebo-controlled } \\
\text { clinical study was performed in } 12 \text { DCCs. Healthy children aged } 1-5 \text { years } \\
\text { were recruited. The subjects were divided into four groups (probiotic, } \\
\text { prebiotic, synbiotic and control); the intervention lasted for } 26 \text { weeks. } \\
\text { Statistical analysis included analysis of variance, Fisher's exact test, chi- } \\
\text { squared, Relative Risk Reduction (RRR), Absolute Risk Reduction (ARR) } \\
\text { and Number Needed to Treat (NNT). Chi-squared analysis for ARI } \\
\text { incidence and duration for the probiotic and synbiotic groups showed } \\
\text { significantly different results compared to the control group ( } \mathrm{p}<0.05 \text { ). The } \\
\text { NNT calculation showed that synbiotics provided the best prevention from } \\
\text { ARI (NNT = } 6.25 \text { ). The use of probiotics, and synbiotics decreased the } \\
\text { incidence of ARI in healthy children, but the best prevention for ARI was } \\
\text { conferred by synbiotics. }\end{array}$ \\
\hline
\end{tabular}

\section{Introduction}

Acute respiratory infection (ARI) in children, especially 1-5 year olds, is still a dominant disease on multiple levels: primary health care (Puskesmas), hospitals and referral hospitals (Kementerian Kesehatan Republik Indonesia, 2007). In RSUD Dr Soetomo, ARI patients were recorded at $12.7 \%$ in 2007 , and this incidence increased to $13.4 \%$ in 2008 (Unit Rawat Jalan RSUD Dr Soetomo, 2008). Meanwhile, according to Wald, the risk of contracting ARI in daycare centres (DCCs) is 1.5-3-times higher than those being cared for at home (Wald, Guerra and Byers, 1991).
Participation in DCCs is a great infection risk factor for children (Louhiala et al., 2001). Often, exposure to infection sources, antibiotic treatments (incorrect according to the indication) and decrease in body immunity are causes of the high ARI incidence (Wantania, Naning and Wahani, 2008). This problem drives scientists to find new alternatives for decreasing ARI risk, namely by increasing body resistance. Thus, the increased interest towards probiotic bacteria is quite understandable.

There are several clinical studies that tested the effect of probiotics in respiratory infection in 
healthy subjects. These studies concluded that probiotics can reduce the severity of respiratory infections and the incidence of lower respiratory tract infection (Hattaka, 2001; Cobo Sanz, Mateos and Munoz-Conejo, 2006). Meanwhile, microflora begins to spread starting from when a baby is born. There are four phases of normal intestinal flora development (Mack et al., 1999): early inception of external microbes $\left(1^{\text {st }}\right.$ and $2^{\text {nd }}$ week of life), the breastfeeding period, complimentary food and breastfeeding cessation and finally conversion to an adult microbiota pattern. During the third and fourth phases, exposure to the environment is very high, and the child will be more prone to respiratory infections, especially those who are cared for in DCCs, where infectious diseases are common. Therefore, there are three strategies to improve the colonisation of normal microflora: elevate the number of normal microflora (probiotic), increase the nutritional substances that will elevate the growth of probiotic bacteria (prebiotic) and combine both microflora and nutritional substrates (symbiotic; Markowiak and Śliżewska, 2017).

Nevertheless, evidence regarding the clinical benefits of these supplements are still sparse, and therefore the effect of prebiotics, probiotics and synbiotics towards preventing ARI is not yet clearly known and requires better evidence through clinical trials. This research's objective was to examine the effects of prebiotics, probiotics and synbiotics contained in formula milk towards preventing ARI for 1to-5-year-old children attending DCCs, with the ultimate goal of reducing the ARI incidence in DCCs.

\section{Materials and methods}

This double-blind, randomised and controlled trial examined healthy 1-5-year-old children at DCCs, each of whom were given prebiotics, probiotics, synbiotics or placebo (control). This research was ethically approved by the Ethical Commission of Airlangga
University Faculty of Medicine, Surabaya, and all respondents were entitled to health protection from health insurance, which covered the maintenance of outpatient and inpatient care during the research and 6 months after it finished. The parents of all participants provided consent for their participation in the study.

\subsection{Samples}

Subjects were recruited at 12 DCCs: Soetomo A DCC, Soetomo B DCC, Airlangga DCC, Ngagel DCC, BPPLSP DCC, Taman Ceria DCC, Telkom DCC and Harapan Aisyah DCC (Surabaya); Intan Citra DCC, Intan Tamasa DCC and Miftahul Jannah DCC (Sidoarjo); and Aisyah DCC (Gresik). The treatment was performed over 6 months (26 weeks); all participants met the inclusion criteria. Subjects were excluded if they were sick since the beginning of the research, lactose intolerant, had a disability/hereditary disease that interferes with respiratory, cardiovacular or digestive system, were allergic to cow's milk and/or had a history of consuming probiotics/prebiotics or food/drinks that contain them during the prior 2 weeks. All samples were collected from the 12 DCCs and were made in order according to the participation start date. The subjects were then randomised to determine groups (A through D). Randomisation was performed by block random sampling; there were four groups: prebiotic (P1), probiotic (P2), synbiotic (P3) and formula milk-only or control (P4).

\subsection{Probiotic, Prebiotic, Synbiotic, Control}

The probiotic treatment contained Bifido BB12 and Lactobacillus casei CRL 431, $1 \times 10^{9}$ colony forming units (CFU)/feeding (within 30 $\mathrm{g}$ formula/150 $\mathrm{mL}$ water). The prebiotic treatment contained galactooligosaccharide (GOS); as much as $840 \mathrm{mg}$ was given per feeding (within $400 \mathrm{mg}$ formula/ $100 \mathrm{~mL}$ water). The synbiotic treatment contained Bifido BB12, L. Casei CRL 431 and GOS, 1 × $10^{9}$ 
CFU/feeding (within $30 \mathrm{~g}$ formula milk/150 mL water). The control contained only formula milk (30 $\mathrm{g}$ formula/150 $\mathrm{mL}$ water).

The treatments were given seven days a week. Each day, the subject consumed a minimum of $600 \mathrm{~mL}$ milk (within the composition of 1 part $/ 30 \mathrm{~mL}$ ). Milk was given three times at the daycare and the rest at home as needed for the day. If milk consumption was less than $600 \mathrm{~mL}$ per day, the participant was excluded.

\subsection{Statistical analysis}

All subjects completed a daily form, which contained information about body weight, milk consumption, temperature and ARI signs and symptoms during the 26-week study. The research team called to check if there were any complaints. Once a week, a medical check-up was performed by the research medical team. Data was compiled and analysed using SPSS. The statistical methods included chi-squared, analysis of variance (ANOVA), Mann-Whitney U test, Kruskall-Wallis test and Fisher's exact test.

Fisher's exact test, the independent t-test and ANOVA were used to test the differences in the incidence of ARI infections. ANOVA was used to test for differences in ARI episode length (in days) in the probiotic, prebiotic, synbiotic and control groups. Relative risk reduction (RRR), absolute risk reduction (ART) and number needed to treat (NTT) were also calculated. RRR is the percentage difference in event rates between treatment and control groups, and thus it shows the possibility of ARI events in the treatment group in proportion to the probability of ARI events in the control group. ARR is the arithmetic difference between event rates over a fixed period of time, while NNT is the number of patients who must be treated during a fixed period of time in order to prevent an event from happening.

\section{Results and discussions}

At the beginning of the study, there were a total of 267 children from 12 DCCs in Surabaya, Sidoarjo and Gresik. Twenty-three children were unable to continue participating due to the exclusion criteria (13 children were allergic to cow's milk, 6 children moved out of town and 4 children rarely drank milk). Two weeks of adaptation were performed before randomisation. During the adaptation period, the formula milk usually consumed by the subjects was gradually substituted with the new formula milk used for the research (without adding any substance). The formula milk's cover and brand were sealed. After the adaptation period, 28 children were unable to continue participating in the research due to several reasons (12 children did not like the milk's taste, 5 children had prolonged diarrhea, 5 children moved out of town and 6 children's parents refused to continue participating).

The remaining children were randomised and divided into four groups: 55 children in the prebiotic group, 53 children in the probiotic group, 54 children in the synbiotic group and 54 children in the control group. During the 26week treatment, 3 children were unable to continue participating. Thus, only 213 children completed the research. The charcteristics of the 213 subjects are presented in Table 1. 
Table 1. The characteristics of study subjects by group.

\begin{tabular}{|l|c|c|c|c|c|}
\hline \multicolumn{1}{|c|}{ Characteristic } & $\begin{array}{c}\text { Prebiotic } \\
(\mathbf{P 1})\end{array}$ & $\begin{array}{c}\text { Probiotic } \\
(\mathbf{P 2})\end{array}$ & $\begin{array}{c}\text { Synbiotic } \\
(\mathbf{P 3})\end{array}$ & Control (P4) & p-value \\
\hline Age (Months) & $38.57 \pm 11.8$ & $35.75 \pm 13.7$ & $34.57 \pm 12.3$ & $36.75 \pm 12.9$ & 0.423 \\
\hline Male & $31(58.5 \%)$ & $26(49.1 \%)$ & $23(42.6 \%)$ & $21(39.6 \%)$ & 0.214 \\
Female & $22(41.5 \%)$ & $27(50.9 \%)$ & $31(57.4 \%)$ & $32(60.4 \%)$ & \\
\hline $\begin{array}{l}\text { Good Nutrition } \\
\text { Mild Malnutrition }\end{array}$ & $\begin{array}{c}48(90.5 \%) \\
5(9.5 \%)\end{array}$ & $\begin{array}{c}47(88.7 \%) \\
6(11.3 \%)\end{array}$ & $\begin{array}{c}46(85.2 \%) \\
8(14.8 \%)\end{array}$ & $\begin{array}{c}47(88.7 \%) \\
6(11.3 \%)\end{array}$ & 0.856 \\
\hline Weight (kg) & $13.62 \pm 3.5$ & $13.04 \pm 3.3$ & $13.20 \pm 3.7$ & $12.77 \pm 3.1$ & 0.450 \\
\hline Siblings $\leq 1$ & $40(75.5 \%)$ & $41(77.4 \%)$ & $40(74 \%)$ & $38(71.7 \%)$ & 0.997 \\
\hline \multicolumn{1}{c}{$>1$} & $13(24.5 \%)$ & $12(22.6 \%)$ & $14(26 \%)$ & $15(28.3 \%)$ & \\
\hline $\begin{array}{l}\text { Smoker at home Yes } \\
\text { No }\end{array}$ & $31(58.5 \%)$ & $27(51 \%)$ & $33(61 \%)$ & $30(56.6 \%)$ & 0.385 \\
\hline $\begin{array}{l}\text { History of ARI } \\
\leq 2\end{array}$ & $22(41.5 \%)$ & $26(49 \%)$ & $21(39 \%)$ & $24(43.4 \%)$ & \\
\hline 2 & $39(73.6 \%)$ & $32(60.4 \%)$ & $33(61 \%)$ & $36(68 \%)$ & 0.332 \\
\hline $\begin{array}{l}\text { Milk Consumption } \\
\text { (average mL/day) }\end{array}$ & $14(26.4 \%)$ & $21(39.6 \%)$ & $21(39 \%)$ & $17(32 \%)$ & \\
\hline
\end{tabular}

Table 2. Comparison of ARI incidence rate, RRR, ARR, NNT and average length (in days) of ARI episodes in probiotic, prebiotic, synbiotic and control groups.

\begin{tabular}{|c|c|c|c|c|c|}
\hline & $\begin{array}{c}\text { Prebiotic } \\
\text { (P1) }\end{array}$ & $\begin{array}{l}\text { Probiotic } \\
\text { (P2) }\end{array}$ & $\begin{array}{c}\text { Synbiotic } \\
\text { (P3) }\end{array}$ & $\begin{array}{c}\text { Control } \\
\text { (P4) }\end{array}$ & $\mathbf{p}$ \\
\hline $\mathbf{N}$ & 53 & 53 & 54 & 53 & - \\
\hline $\begin{array}{c}\text { Incidence } \\
\text { Rate }\end{array}$ & $0,036^{\mathrm{a}}$ & $0,030^{\mathrm{b}}$ & $0,026^{\mathrm{c}}$ & 0,044 & 0,0429 \\
\hline RRR* $^{*}$ & $8 \%$ & $25 \%$ & $27 \%$ & - & - \\
\hline ARR* & $5 \%$ & $15 \%$ & $16 \%$ & - & - \\
\hline NNT* & 20 & 6,6 & 6,25 & - & - \\
\hline Days/episode & $2,62 \pm 2,92^{d}$ & $2,26 \pm 3,23^{\mathrm{e}}$ & $1,78 \pm 2,26^{\mathrm{f}}$ & $5,85 \pm 8,28$ & 0,041 \\
\hline $\begin{array}{l}p=0.247 \\
p=0.045 \\
p=0.0079\end{array}$ & & & $\begin{array}{l}p=0.157 \\
p p=0.031 \\
\mathrm{~d}^{\mathrm{d}} p=0.010\end{array}$ & & \\
\hline
\end{tabular}


From the table 2, the ARI incidence in prebiotic, probiotic, synbiotic and control groups showed significant $\mathrm{p}$ result among those four groups $(p=0,0429)$, Chi Square test was further performed to compare between groups. From the chi square test results between Probiotic and Control groups, and Synbiotic and Control groups, significantly different results were obtained $(p<0,05)$, while the chi square test result between Prebiotic and Control groups obtained unsignificantly different result $(\mathrm{p}>0,05)$.

The ARI incidence was significantly different among the treatment groups $(\mathrm{p}=$ 0.0429; Table 2). A chi-squared test was performed to compare between groups; the probiotic compared to control and synbiotic compared to control were significantly different $(\mathrm{p}<0.05)$, but there was no difference between the prebiotic and Control groups $(\mathrm{p}>0.05$; Table $2)$.In the prebiotic group, the RRR was $8 \%$, a value that indicates there will be a reduction in ARI events in as many as $8 \%$ of subjects after prebiotic treatment. The prebiotic group ARR was $5 \%$, which results in an NNT of 20 . These results imply that we should treat 20 healthy children for 6 months to prevent ARI from occuring. In the probiotic group, the RRR was $25 \%$; there would be a reduction in ARI events as many as $25 \%$ of subjects after probiotic treatment. The probiotic group ARR was $15 \%$ and the NNT was 6.6; thus, we should treat 6.6 healthy children for 6 months to prevent ARI. Finally, the synbiotic group RRR was $27 \%$, a value that indicates there will be a reduction in ARI events in as many as $27 \%$ of subjects after synbiotic treatment. The synbiotic group ARR was $16 \%$ and the NNT was 6.25 , so we should treat 6.25 healthy children for 6 months to prevent ARI from occuring.

The length per ARI episode was 2.62 (standard deviation [SD] 2.92) days for the prebiotic group, 2.62 (SD 3.23) days for the probiotic group, 1.78 (SD 2.26) days for the synbiotic group and 5.85 (SD 8.28) days for the control group. There was a significant difference in this measure among the groups, where the control group value was higher than the other three groups $(p<0.05)$. Chi-squared test results showed significant differences between the probiotic and control groups and the synbiotic and control groups $(\mathrm{p}<0.05)$, but no difference between the prebiotic and control groups (Table 2 ). Thus, the probiotic and synbiotic group were more effective in reducing the ARI duration. To evaluate the homogeneity of the sample, we analysed numerous variables between the treatment and control groups before the study began. Variables analysed included: subject characteristics (age, gender, weight and nutritional status), environmental factors (number of siblings, smokers in the house and ARI and allergy history from the last 3 months) and random factors such as antibiotic usage. There were no differences between the treatment (probiotic, prebiotic and synbiotic) and control groups. Thus, there were no specific conditional differences among the groups before the study commenced.

There was a decrease in ARI cases in the prebiotic compared to the control group, but this difference was not significant. Further, the length per ARI episode between the prebiotic and control groups was not significantly different. Thus, prebiotic exposure did not affect ARI incidence or length. This finding may be related to the subjects' age (11-59 months with an average of $38.57 \pm 11.8$ months). At that age, the amount of endogenous normal flora has begun to decline, and thus the administration of prebiotic (nutrition for endogenous normal flora) at that age would be heavily dependent on the remaining amount of endogenous normal flora. If the amount is still adequate, then the resulting mucosa colonisation will be strong and provide mucosal protection and adequate adaptive immunity, which will ultimately provide protection from ARI (Fijan, 2014).

Research on the effect of prebiotics towards ARI was previously done using a randomised 
double-blind study with 259 aterm babies with a history of an atopic parent. Half (129 babies) were given fructooligosaccharides (FOS) and GOS supplements while the remaining 130 babies comprised the control group. The treatment was administered from the first 2 weeks to 6 months of life. Infectious disease, ARI, urinary tract infection and the relapse of infectious disease in both groups was evaluated. The prebiotic group had fewer ARI cases, reduced ARI relapse and less antibiotics usage compared to the control group (Arslanoglu et al., 2008).

The probiotic group showed better results than the prebiotic group. The ARI incidence of 0.030 represented a $25 \%$ decrease when compared to the control group. The probiotic group would require treating 6.6 children to prevent 1 child from contracting ARI. This finding is in line with a previous study that showed probiotics significantly decrease symptom severity, common cold duration and fever length, although there are no apparent effect on the overall incidence of respiratory tract infections (de Vrese et al., 2006).

The synbiotic group showed an incidence of 0.026 , which, when compared to the control group, represented a $27 \%$ decrease in ARI cases. The synbiotic group would require treating 6.25 children to prevent 1 from contracting ARI. Research on the effect of synbiotics towards ARI was examined in a previous randomised, double-blind clinical study. The trial, performed between November 2000 and March 2003 with 1,018 pregnant mothers with a history of atopy, were given synbiotic supplementation, consisting of four probiotics (Lactobacillus rhamnosus GG and LC705, Bifidobacterium breve $\mathrm{Bb} 99$ and Propionibacterium freudenreichii ssp) and GOS for 4 weeks before giving birth and during the first 6 months of the baby's life. The symbiotic group exhibited fewer ARI cases and reduced antibiotic prescriptions compared to the control group (Kukkonen et al., 2006). These results show that both prebiotic and probiotic exposure are beneficial to prevent ARI, but the prebiotic effects in this study were statistically insignificant. This data fits the theory of a common mucosal immune system (CMIS) pathway to boost the immune response, by treatment in the intestinal mucosa, and the resulting immune response on other mucosa, namely the respiratory mucosa.

Although the probiotics and synbiotics were more effective in boosting the immune response through the CMIS pathway compared to prebiotics, even when the mild probiotic protective effects against ARI are overcome by the infection, the remaining immune response is still effective in decreasing the length of the ARI episode. This phenomenon may be explained by previous research where administration of fermented milk that contained the probiotic $L$. casei DN 114001 elevated natural killer (NK) cell activity and increased monocyte capacity compared to the control group (Parra et al., 2004). Meanwhile, another study that involved consuming milk that contained Bifidobacterium lactis HN019 showed increased phagocyte capacity on peripheral polymorphonuclear leucocytes compared to placebo (Arunachalam, Gill and Chandra, 2000). Also, consumption of formula milk with Lactobacillus reuteri or $B$. lactis BB-12 for 12 weeks did not decrease the average number of respiratory tract disease, but did reduce the illness episode, absence from daycare and antibiotic prescription for babies age 4-10 months (Weizman, Asli and Alsheikh, 2005).

\section{Conclusions}

ARI incidence in children aged 1 to 5 years at DCCs decreased by $8 \%, 25 \%$ and $27 \%$ after receiving formula with probiotics, prebiotics and synbiotics, respectively, compared to the control group. ARI duration length (days per episode of ARI) was significantly reduced with the addition of probiotics and synbiotics but not with prebiotics in formula milk. The best 
prevention for ARI, shown by NNT, is provided by synbiotics.

\section{References}

Arslanoglu, S. et al. (2008) 'Early dietary intervention with a mixture of prebiotic oligosaccharides reduces the incidence of allergic manifestations and infections during the first two years of life', The Journal of Nutrition, 138, pp. 1091-1095.

Arunachalam, K., Gill, H. S. and Chandra, R. K. (2000) 'Enhancement of natural immune function by dietary consumption of Bifidobacterium lactis (HN019).', European journal of clinical nutrition. England, 54(3), pp. 263-267.

Cobo Sanz, J., Mateos, J. and Munoz-Conejo, A. (2006) 'Effect of Lactobacillus casei on the incidence of infectious conditions in children', Nutr Hosp, 21, pp. 547-551.

Fijan, S. (2014) 'Microorganisms with claimed probiotic properties: an overview of recent literature', International Journal of Environmental Research and Public, 11(5), pp. 4745-4767.

Hattaka, K. (2001) 'Effect of long term consumption of probiotic milk on infections in children attending day care centres: double blind, randomised trial', $B M J, 322$, p. 1327.

Kementerian Kesehatan Republik Indonesia (2007) Profil Kesehatan Indonesia.

Kukkonen, K. et al. (2006) 'Effect of probiotics on vaccine antibody responses in infancy A randomized placebo-controlled doubleblind trial', Pediatric Allergy and Immunology, 17(6), pp. 416-421. doi: 10.1111/j.1399-3038.2006.00420.x.

Louhiala, P. et al. (2001) 'Form of day care and respiratory infections among Finnish children', American Journal of Public Health, (85), pp. 1109-1112.

Mack, D. R. et al. (1999) 'Probiotics inhibit enteropathogenic E. coli adherence.pdf', (5), pp. 941-950.

Markowiak, P. and Śliżewska, K. (2017) 'Effects of Probiotics, Prebiotics, and Synbiotics on Human Health. Nutrients.
2017;9(9):1021', Nutrients, 9, p. 1021.

Parra, D. et al. (2004) 'Monocyte function in healthy middleaged people receiving fermented milk containing Lactobacillus casei', The Journal of Nutrition, Health and Aging, 8, pp. 208-211.

Unit Rawat Jalan RSUD Dr Soetomo (2008) Laporan Unit Rawat Jalan. Surabaya.

De Vrese, M. et al. (2006) 'Probiotic bacteria reduced duration and severity but not the incidence of common cold episodes in a double blind, randomized, controlled trial', Vaccine, 24, pp. 6670-6674.

Wald, E., Guerra, N. and Byers, C. (1991) 'Frequency and severity of infections in day care: three-year follow-up', Journal of Pediatrics, 118, pp. 509-514.

Wantania, J., Naning, R. and Wahani, A. (2008) 'Infeksi Respiratori Akut', in Buku Ajar Respirologi Anak, pp. 268-276.

Weizman, Z., Asli, G. and Alsheikh, A. (2005) 'Effect of a probiotic infant formula on infections in child care centers: comparison of two probiotic agents', Pediatrics, 115, pp. 5-9.

\section{Acknowledgment}

The authors thank all the teams who worked on this study. 